\title{
Age, growth, and population structure of the smooth clam Callista chione in the eastern Adriatic Sea
}

\author{
Daria Ezgeta-Balić $\cdot$ Melita Peharda $\cdot$ \\ Christopher A. Richardson • Marina Kuzmanić • \\ Nedo Vrgoč • Igor Isajlović
}

Received: 4 March 2010/Revised: 27 October 2010/Accepted: 30 October 2010/Published online: 16 November 2010

(C) Springer-Verlag and AWI 2010

\begin{abstract}
The age, growth, and population structure of the smooth clam Callista chione were determined from samples collected by hydraulic dredge and SCUBA at four locations in the eastern Adriatic during 2007 and 2008. The age of 436 clam shells was determined from internal growth lines present in shell sections, and the timing of growth line formation was ascertained from monthly collections of clams to occur between August and September when sea water temperatures were maximal. In addition, age of 30 older individuals was verified with acetate peels of polished and etched shell sections. Differences were apparent in the age structure and growth rates of clams collected from the four locations studied. Von Bertalanffy growth (VBG) curves obtained for clams from these locations were $L_{t}=72.4\left(1-\mathrm{e}^{-0.25(\mathrm{t}-2.68)}\right)$ (Rab Island), $L_{t}=74.5 \quad\left(1-\mathrm{e}^{-0.15(\mathrm{t}+0.57)}\right) \quad($ Pag $\quad$ Bay $), \quad L_{t}=79.3$ $\left(1-\mathrm{e}^{-0.34(\mathrm{t}-0.97)}\right) \quad$ (Cetina estuary), and $L_{t}=82.5$ $\left(1-\mathrm{e}^{-0.11(\mathrm{t}+2.88)}\right)$ (Kaštela Bay). The age of the clams ranged between 3 and 44 years; median clam ages were similar at three of the four locations $(14,12$, and 12 years, respectively), but was significantly lower in the Cetina estuary (4 years). The VBG growth constants recorded from clams were within the range of values obtained for this species by previous authors. The observed local
\end{abstract}

Communicated by H.-D. Franke.

D. Ezgeta-Balić · M. Peharda $(\varangle) \cdot$ M. Kuzmanić · N. Vrgoč

I. Isajlović

Institute of Oceanography and Fisheries,

Šetalište Ivana Meštrovića 63, 21000 Split, Croatia

e-mail: melita@izor.hr

C. A. Richardson

School of Ocean Sciences, Bangor University,

Menai Bridge, Anglesey LL59 5AB, UK differences in population structure indicate different levels of exploitation and illustrate the need to establish long-term strategies for a sustainable exploitation of smooth clams in the Croatian Adriatic.

Keywords Adriatic Sea - Bivalve · Age ·

Callista chione . Growth P Population structure

\section{Introduction}

The smooth clam Callista chione (Linnaeus, 1758), a shallow-burrowing suspension feeding venerid bivalve, inhabits sandy sediments in coastal waters at depths down to $180 \mathrm{~m}$. It is widely distributed in the Atlantic and Mediterranean, including the Adriatic Sea (Zavodnik and Šimunović 1997; Poppe and Goto 2000). Callista chione is a large (up to $100 \mathrm{~mm}$ ) edible bivalve that is commercially fished in some areas of the Mediterranean (Poppe and Goto 2000). Smooth clam is usually collected by hand by SCUBA divers working in shallow coastal waters $(<10 \mathrm{~m})$ along the Croatian Adriatic. Catches are sold in local markets and/or to local restaurants. The fishery is unregulated and there appears to be no scientific data relating to the clams growth, age or recruitment patterns in Croatian coastal waters.

Previous studies that have been conducted on $C$. chione include an analysis of its reproductive cycle in the coastal waters of Màlaga, southern Spain (Tirado et al. 2002) and in southwestern Portugal (Moura et al. 2008), and its population dynamics in the eastern Mediterranean waters off Greece (Metaxatos 2004). Furthermore, its age and shell growth rate has been determined along latitudinal gradients (Hall et al. 1974) in the English Channel (Forster 1981), in the Bay of Trieste, Italy (Keller et al. 2002) and 
from shallow depths $(<5 \mathrm{~m})$, in the Thracian Sea, northeastern Mediterranean (Leontarakis and Richardson 2005) and from the southwestern coast of Portugal (Moura et al. 2009). Callista chione is a moderately long-lived bivalve that can live for $>40$ years (Forster 1981), although more commonly individuals up to a maximum age of 16 years (Leontarakis and Richardson 2005) or 17 years (Hall et al. 1974; Metaxatos 2004; Moura et al. 2009) have been recorded in most of the studied populations. The population structure of $C$. chione has only been documented on one occasion in a population from Euboikos Gulf (Greece) in the eastern Mediterranean where Metaxatos (2004) demonstrated that the population consisted mainly of young clams $<6$ year old $(71 \%)$, while only $2 \%$ of the clams were older than 10 years.

The age of a bivalve shell has traditionally been determined using surface growth rings or checks that can be clearly seen on the shell surface (Richardson 2001), and they are particularly clear in C. chione (Forster 1981). The rings can be more easily discerned when the shell surface is illuminated from inside by a bright light source (Leontarakis and Richardson 2005). During the early years of shell growth, the rings are widely spaced and are easy to identify. In later life (20+ years), however, they are deposited closely together, and at the shell margin, they are not always easily discernible. An alternative method is to count the number of growth lines visible in polished and etched radial (umbo to shell margin) shell sections (Richardson 2001).

In the Mediterranean and surrounding Seas, an increased demand for sea food has resulted in the intensified exploitation of many groups of marine organisms, including many bivalve species. In Croatia, although $C$. chione is not traditionally exploited for human consumption, changes in market demands caused primarily in the last decade by the development of tourism have encouraged the commercial exploitation of this bivalve (Matijaca, pers. comm.). Currently, there are no official statistics on the quantities of commercially harvested smooth clams and to date, no studies have been undertaken on $C$. chione in the Croatian Adriatic Sea. The present study was performed in order to gain an insight into the ecology of $C$. chione in the area and to obtain some basic data on this increasingly exploited species that are necessary for its sustainable management.

\section{Materials and methods}

Samples of $\sim 100$ smooth clams $C$. chione of a range of sizes $(30-88 \mathrm{~mm})$ were selected from catches obtained by hydraulic dredge deployed in depths from 2.5 to $6 \mathrm{~m}$ in coastal waters along the eastern Adriatic during May 2008 in the estuary of the Cetina River and in November 2008 around Rab Island and Pag Bay (Fig. 1). For a detailed description of the hydraulic dredge sampling procedures, see Peharda et al. (2010). A further 29 and 41 clams were collected each month from Kaštela Bay (Fig. 1) by commercial SCUBA divers between July 2007 and June 2008. Following collection, all the clams were stored frozen for later analysis.

In the laboratory, the monthly frozen samples of $C$. chione from Kaštela Bay were thawed and the condition indices of the clams determined. Shell length (anteriorposterior axis) and shell height (umbo-rim axis) of each clam were measured with vernier callipers to the nearest $0.1 \mathrm{~mm}$. The shells were air-dried and archived for further study. The flesh was removed from the shell valves by 'cooking' groups of five clams in $1.5 \mathrm{~L}$ of boiling water for 5 min until the flesh detached from the shell valves. Wet 'cooked' flesh weight and air-dried dry shell weight of each clam were determined to the nearest $0.01 \mathrm{~g}$ using a top

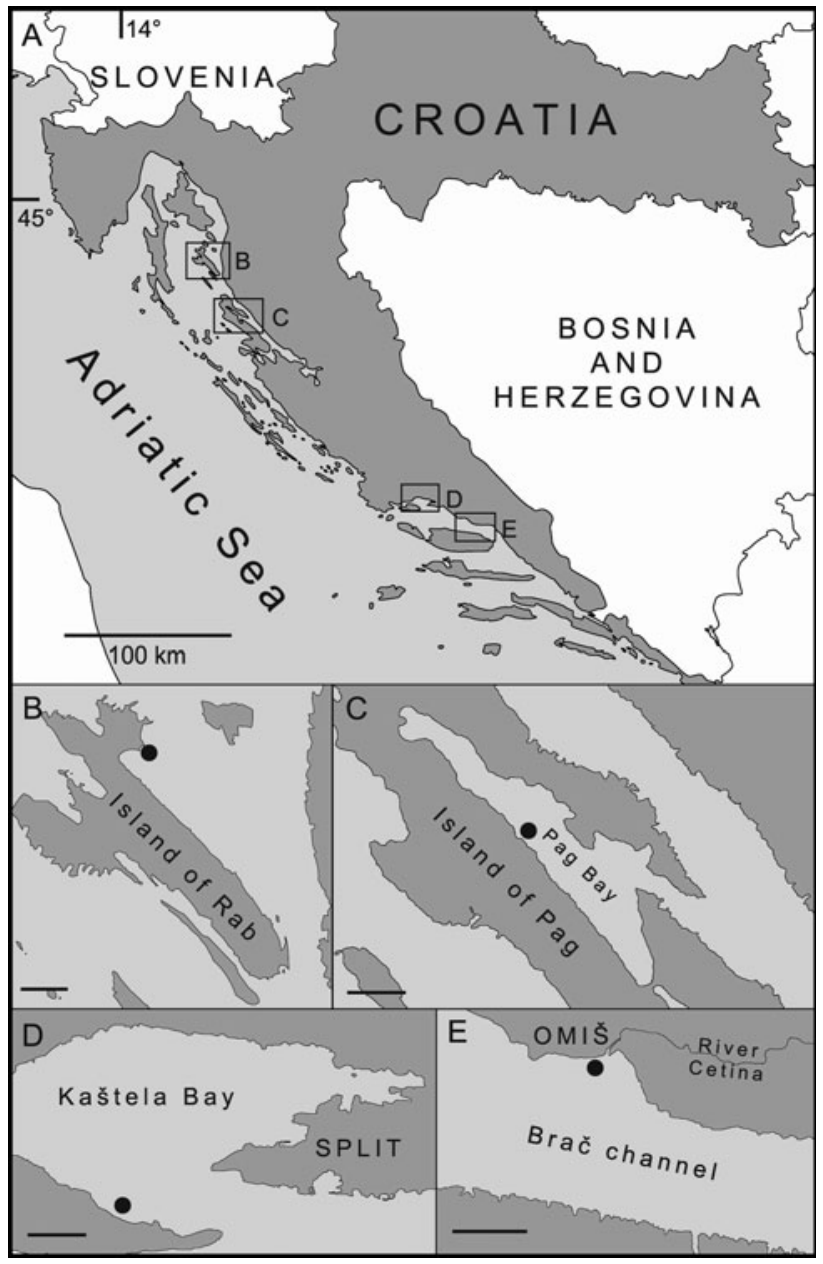

Fig. 1 Map of the coastline of Croatia, Adriatic Sea, to show the four sampling stations (a); Island of Rab (b), Pag Bay (c), Kaštela Bay (d), Brač channel (e). The scale bar on $\mathbf{b}-\mathbf{e}$ is $2 \mathrm{~km}$ 

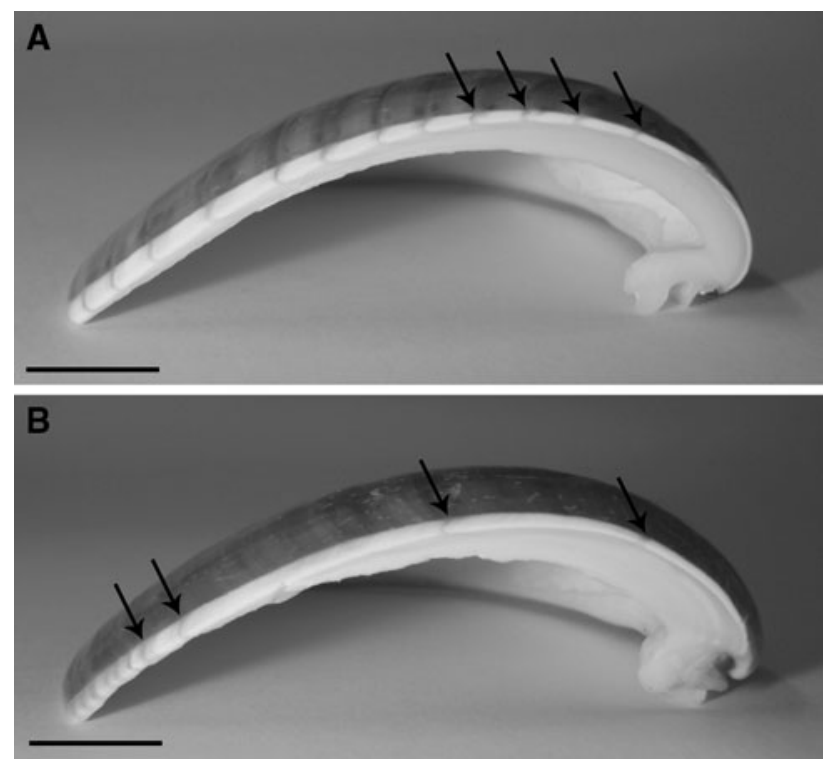

Fig. 2 Radial section of Callista chione shells collected from Rab Island (a) and the estuary of the Cetina River (b). The scale bar on $\mathbf{a}$ and $\mathbf{b}$ is $1 \mathrm{~cm}$

loading balance. The condition index (CI) of these clams was determined as the ratio between wet 'cooked' flesh weight and the sum of the 'cooked' flesh weight plus shell weight (see Davenport and Chen 1987). The non-parametric Kruskal-Wallis test was used to investigate significant differences in clam CI between months.

Clams collected from around Rab Island, Pag Bay, and the estuary of the Cetina River were thawed, and the shell length and shell height of each clam were measured to the nearest $0.1 \mathrm{~mm}$. The age of the $C$. chione shells was determined from the internal growth lines present in shell sections. Initially, the annual deposition of the lines was established using the monthly collected Kaštela Bay shells. The interpretation of the growth lines was then used to ascertain the age of $\sim 100$ clam shells collected from this location in a period from July to September 2007 and from each of the three other locations. These data were then used to estimate the growth of the clams from the different locations.

The archived left shell valve from each of the clams was sectioned from the umbo to the shell margin along the axis of maximum shell growth using a Struers Labotom 3 cutoff machine. The growth lines were identified in the cut section without first embedding in resin (Fig. 2). To determine the timing of growth line formation using the monthly collected clams, the distance between the last clearly visible growth line and the shell margin in 104 shells (8-10 shells month ${ }^{-1}$ ) (range $44-66 \mathrm{~mm}$ ) from Kaštela Bay was measured. Following validation of an annual periodicity of growth line formation, each clearly visible internal line was identified along the shell section and the distance between the umbo and each line was

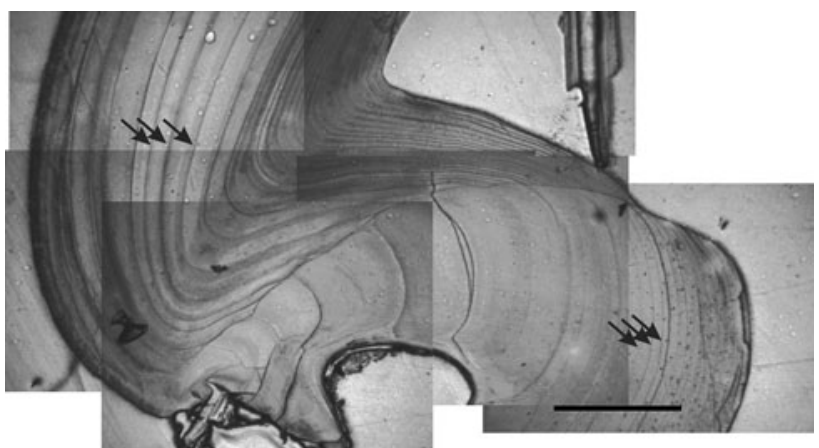

Fig. 3 Photomicrograph of an acetate peel of a section through the hinge region of the shell of Callista chione from Rab Island. Black arrows indicate the positions of three growth lines in the hinge and inner shell layer. Scale bar 1,000 $\mu \mathrm{m}$

measured with an eyepiece graticule to a precision of $0.1 \mathrm{~mm}$. Only five shells $(1 \%)$ were unreadable and these were omitted from the analysis. The relationship between shell length and shell height is described by the following equation:

$L=2.28+1.27 H \quad\left(N=441, r^{2}=0.92\right)$

The right shell valves of a further thirty shells $(68-87 \mathrm{~mm})$ whose left valves had been sectioned and their age determined were embedded in Metaset resin (Buehler UK Ltd.) (Richardson 2001; Leontarakis and Richardson 2005). The embedded shells were sectioned from the umbo to the shell margin, the cut surfaces ground on trimite (wet and dry paper) (400-2,000 grit) and polished using a soft cloth impregnated with diamond paste. The polished cut shell sections were washed in detergent, air-dried, and etched in $0.1 \mathrm{M} \mathrm{HCl}$ for $30 \mathrm{~min}$ and again washed in water and air-dried. Acetate peel replicas of the polished and etched shell sections were prepared (Richardson et al. 1979). The number of growth lines in the hinge region in the acetate peel replicas of the shell sections was counted (Fig. 3). This was undertaken to compare the ages of the clam shells obtained from the unembedded shell sections with those ascertained from acetate peel replicas of resin-embedded shells. This comparison was necessary because in older shells, the lines became compressed at the shell margin and it was unclear from the un-embedded shell sections whether all of the growth lines had been identified.

From the age and length data, the birth year of each clam was established and recruitment frequency data were plotted to investigate whether specific years of recruitment of individuals into the three populations sampled with the hydraulic dredge had occurred. All the age at length data and annual incremental data were fitted to the Von Bertalanffy growth function for length i.e. $L_{t}=L_{\infty}(1-$ $\left.\mathrm{e}^{-k\left(t-t_{0}\right)}\right)$ where $L_{t}$ is the shell length at time $t, L_{\infty}$ is the asymptotic maximum length and $t_{0}$ is the length at time 


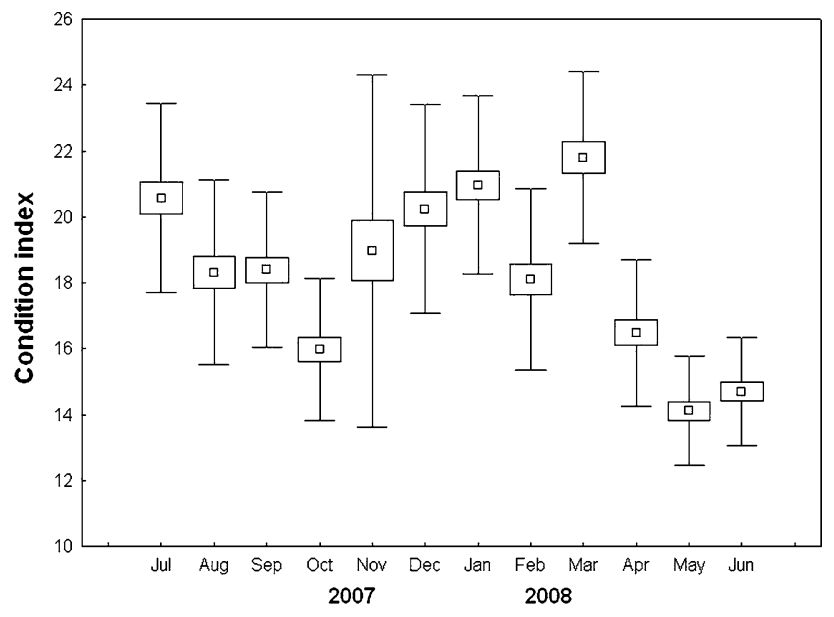

Fig. 4 Seasonal variation in the condition index of Callista chione collected from Kaštela Bay. Values are means, standard error (box) and standard variation (whisker)

zero. The growth coefficients ( $L_{\infty}$ and $k$ ) were also estimated using the annual increment data obtained from measurements of the distances between the annual increments observed in shell section using a Gulland-Holt plot where annual incremental growth rates were plotted against shell heights and a growth function constructed. This method was applied only up to the 15 th growth lines due to small growth at older age. Growth performance index ( $\varnothing^{\prime}=\log k+$ $2 \log L_{\infty}$ ) was applied for comparison of growth among different populations (see Sparre and Venema 1998).

\section{Results}

Significant seasonal differences were noted in the condition indices (CIs) of Callista chione (Kruskal-Wallis $H=186.62, P<0.001$; Fig. 4). The highest mean CIs were recorded for clams collected in early spring (March $=21.8 \pm 2.61)$, and mean values of over 20 were also noted in July, December, and January. The lowest mean CIs were recorded in May and June $(14.1 \pm 1.65$ and $14.7 \pm 1.66$, respectively). Results of our study indicate that $C$. chione in Kaštela Bay reproduce several times per year over the study period.

Growth lines were clearly visible directly in radial shell sections (Fig. 2) and microscopically in acetate peel replicas of the hinge region of the shell including the inner shell layer (Fig. 3). An annual periodicity of line formation was validated using sections from small shells collected monthly in Kaštela Bay (Fig. 5). A dark growth line representing slow shell deposition was visible at or very near the margin of shells collected during the period July to November. Based on these data, August 1st was assigned as an 'annual birthday' and the interpretation of an annual

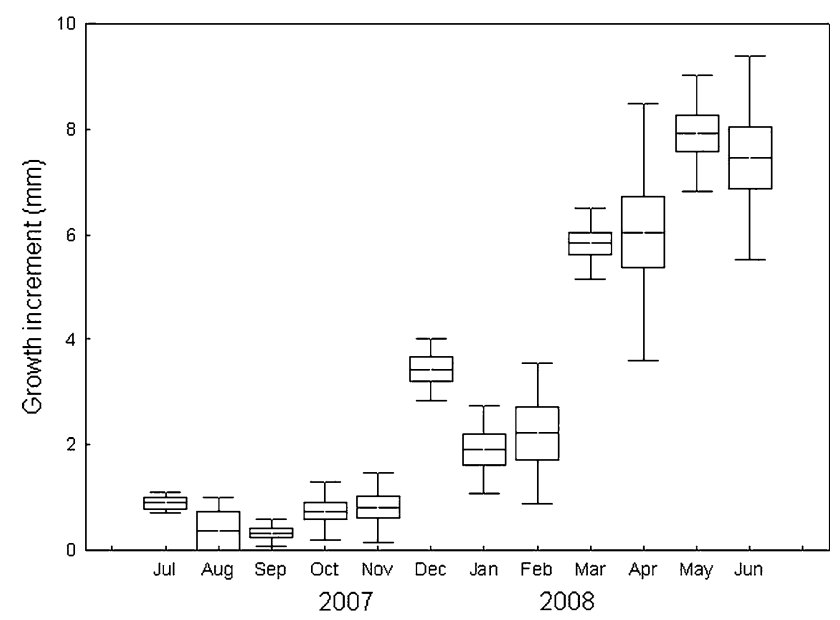

Fig. 5 Seasonal variation in the distance between the last growth line and the shell margin (growth increment width) in clam Callista chione shells collected monthly between July 2007 and June 2008 from Kaštela Bay

periodicity was used to estimate the age and determine the settlement date and growth rate of $C$. chione shells from the different locations. Growth line formation coincided with the warmest seawater temperatures, and shell growth was fastest between February and June.

The estimated ages of 98 shells collected from Kaštela Bay between July and September 2007 ranged between 4 and 19 years with a median age of 12 years. A greater range of ages was found in shells from the other three locations. The ages of shells from the Rab and Pag Island locations ranged between 4 and 44 years $(N=119$, median age $=14$ years $)$ and between 4 and 42 years $(N=103$, median age $=11$ years), respectively. Shells from the estuary of the Cetina River had a mean age that was lower than at the other locations $(N=116$, median age $=4$ years, range 3-37 years). Interrogation of the clams' birth dates (Fig. 6) suggests that successful settlement and survival of clams at Rab Island varied considerably among years. For example, during the late seventies, late eighties, mid-nineties, and early noughties there appeared to be greater recruitment than at other times e.g. the early eighties and early nineties. However, as this is obvious in only one population, the data basis is too small for significance. Significant differences between local populations were noted with respect to population structure (Fig. 7). Large numbers of shells older than 15 years $(32 \%)$ were found only in Rab area. By comparison, in Pag Bay, only $5 \%$ of the analyzed shells were older than 15 years, i.e. recruited into the population before 1993. In this population, bivalves born between 1995 and 2001 dominated the population. In Cetina river estuary, the majority of the clams were recruited after 2000. These data may indicate variations in recruitment success and/or exposure to different fishing pressure among sampling areas. 
Fig. 6 Recruitment frequency of Callista chione into three local populations: a Rab Island; b Pag Bay; c estuary of the Cetina River

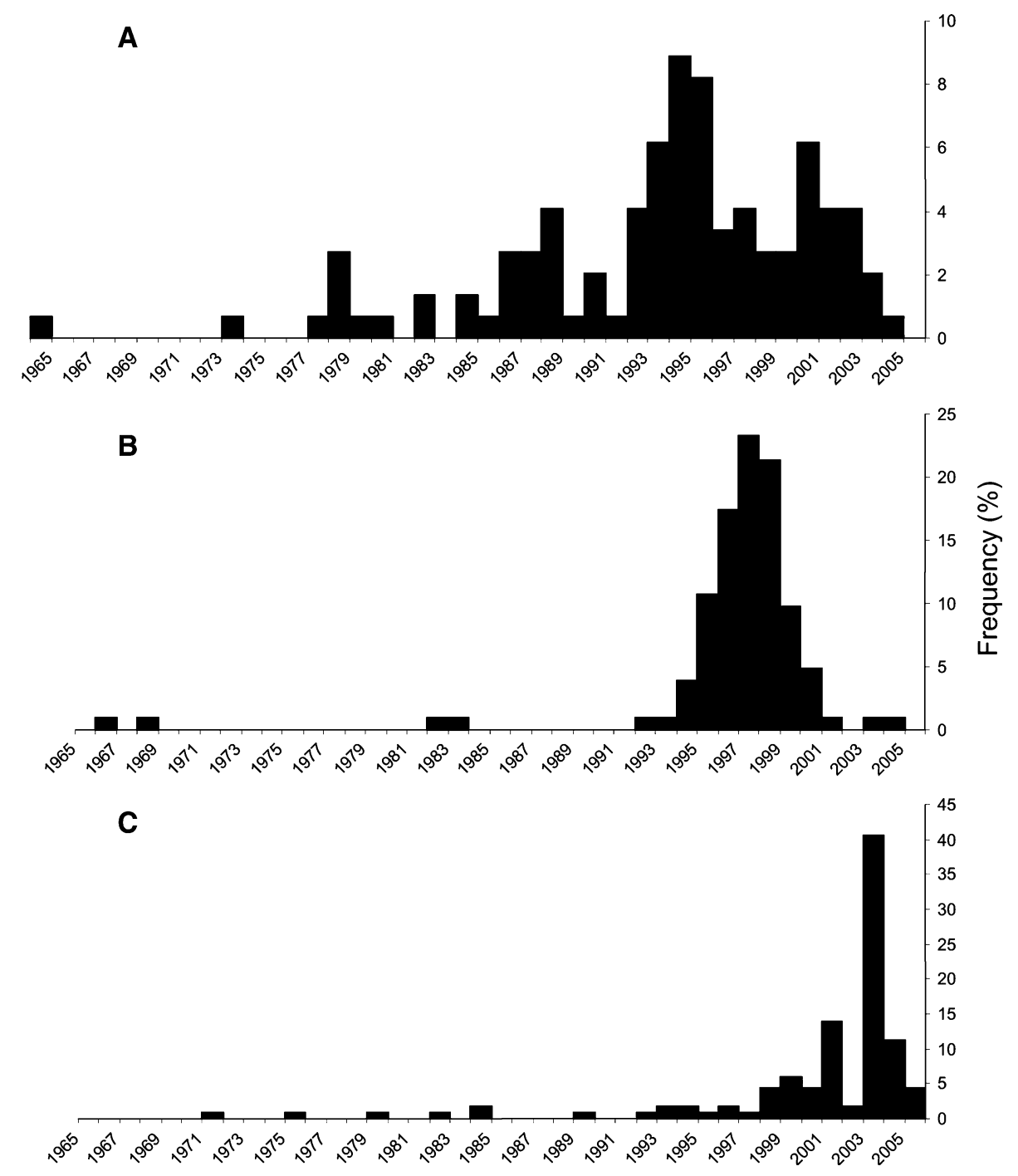

Figure 7 shows that at all four locations studied shell deposition is fastest during the first 5-10 years of a clam's life (6-10 mm year $\left.{ }^{-1}\right)$ with shells attaining a length between 60 and $70 \mathrm{~mm}$. After about 10 years, shell deposition quickly slows down to $\sim 1 \mathrm{~mm}_{\text {year }}{ }^{-1}$. The Gulland-Holt method was applied to the growth increment data generated from measurements of the first fifteen growth increments to estimate $L_{\infty}$ and $k$ (Table 1). Only data for the first 15 years of shell growth were used since growth significantly slows down and the measurement of narrow older growth increments is less precise in shell cross-sections. By comparison, the population growth curve data generated from the length at age data are shown in Table 2. Values for shell growth rates (i.e. $L_{\infty}$ and $k$ ) for clams collected at four locations are presented in Tables 1 , 2; Figs. 7, 8. Clams from the Cetina River estuary displayed the fastest shell growth rates, reaching a length of $70 \mathrm{~mm}$ within the first 7 years of their life. For clams from the Cetina River estuary, the estimated VBG coefficients using the population data and the incremental data were similar $\left(L_{\infty}=79.30\right.$ and $78.57 \mathrm{~mm}$, respectively), and the $k$ values were almost identical $\left(0.32\right.$ and 0.34 year $^{-1}$, respectively). For clams from Rab Island, the growth estimates calculated by the Gulland-Holt plot were $L_{\infty}=85.87 \mathrm{~mm}$ and $k=0.11$ year $^{-1}$, while the values for the clam populations were $L_{\infty}=72.41 \mathrm{~mm}$ and $k=0.25$ year $^{-1}$. Clam shells collected in Pag and Kaštela bay had similar $L_{\infty}$ and $k$ values when the same method was used, but for both locations, population data produced $L_{\infty}$ and $k$ values, which differed from those calculated from incremental data.

\section{Discussion}

The age and growth of bivalves and the role of environmental factors in controlling shell deposition have been documented in numerous previous studies using external 
Fig. 7 Age at length data obtained from the annually resolved growth lines in the shells of individual Callista chione collected from four locations: Rab Island (a), Pag Bay (b), Kaštela Bay (c), and estuary of the Cetina River (d). Von Bertalanffy growth curves fitted to the data

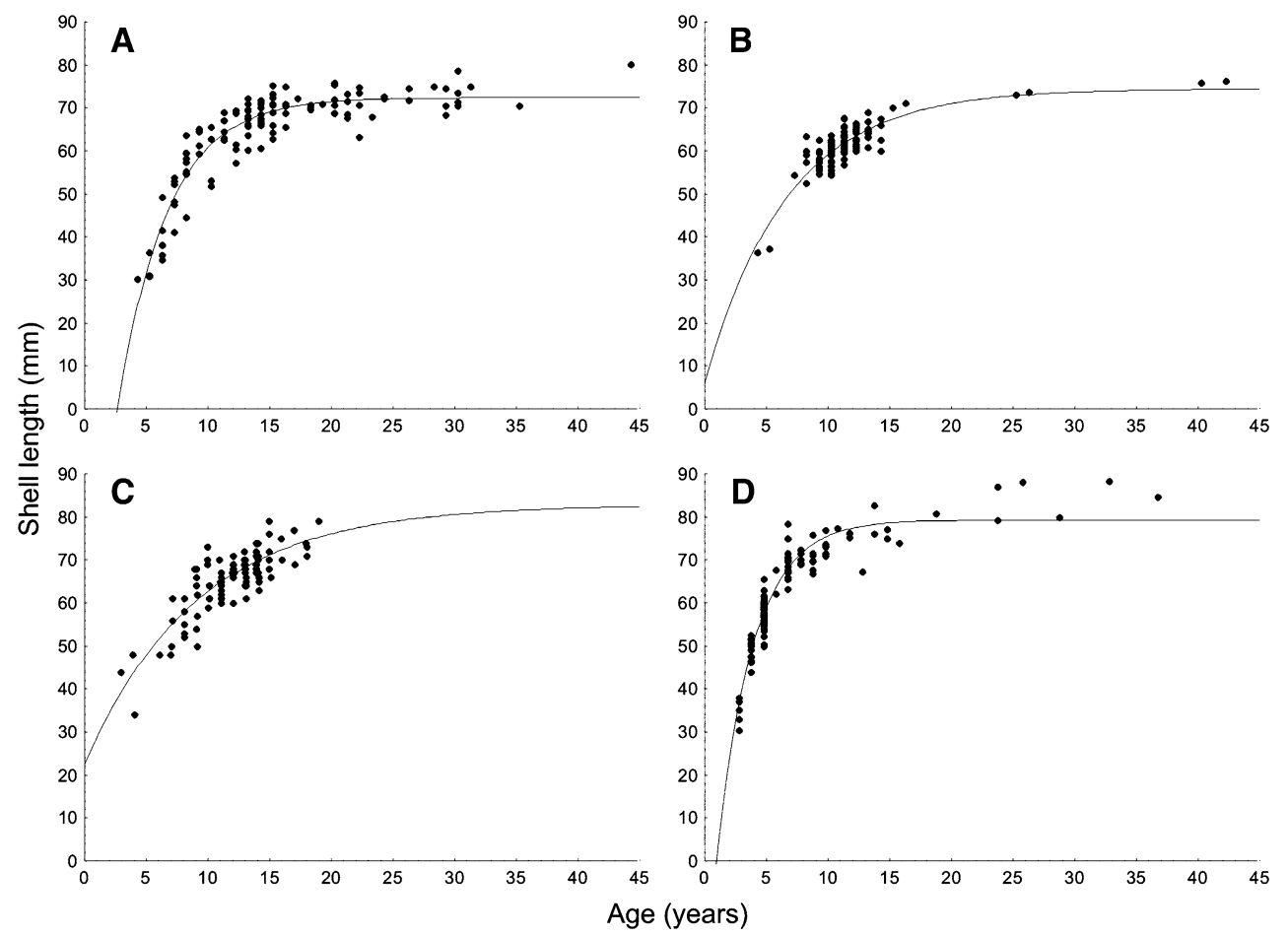

Table 1 Gulland-Holt equations estimated from measurements of shell growth in Callista chione shell sections

\begin{tabular}{lllllll}
\hline Study area & Gulland-Holt equation & $r^{2}$ & $k$ year $^{-1}$ & $H_{\infty}$ & $L_{\infty}$ & $\phi^{\prime}$ \\
\hline Rab Island & $Y=6.595-0.100 X$ & 0.514 & 0.11 & 65.8 & 85.9 & 2.87 \\
Pag Bay & $Y=11.734-0.231 X$ & 0.816 & 0.23 & 50.8 & 66.7 & 3.01 \\
Kaštela Bay & $Y=11.358-0.211 X$ & 0.699 & 0.21 & 53.8 & 70.7 & 3.02 \\
Cetina estuary & $Y=19.088-0.316 X$ & 0.791 & 0.32 & 60.1 & 78.6 & 3.29
\end{tabular}

$r^{2}$ coefficient of determination; Von Bertalanffy growth parameters estimated from Gulland-Holt equation: $k$ growth constant $\left(k\right.$ year $\left.^{-1}\right)$; $H_{\infty}$ asymptotic height $(\mathrm{mm}) ; L_{\infty}$ asymptotic length $(\mathrm{mm})$ calculated from the shell length and shell weight relationship; $\emptyset^{\prime}$ growth performance index

Table 2 Comparison of the estimated Von Bertalanffy growth parameters for Callista chione collected in four sampling areas

\begin{tabular}{lllrll}
\hline Study area & $k$ year $^{-1}$ & \multicolumn{1}{l}{$L_{\infty}$} & \multicolumn{1}{c}{$t_{0}$} & \multicolumn{1}{c}{$r^{2}$} & $\phi^{\prime}$ \\
\hline Rab Island & 0.25 & 72.4 & 2.68 & 0.932 & 3.12 \\
Pag Bay & 0.15 & 74.5 & -0.57 & 0.870 & 2.92 \\
Kaštela Bay & 0.11 & 82.8 & -2.88 & 0.850 & 2.88 \\
Cetina estuary & 0.34 & 79.3 & 0.97 & 0.951 & 3.33 \\
\hline
\end{tabular}

$\overline{k \text { growth constant }\left(k \text { year }^{-1}\right), L_{\infty} \text { asymptotic length }(\mathrm{mm}), r^{2} \text { coeffi- }}$ cient of determination, $t_{0}$ initial condition parameter, and $\emptyset^{\prime}$ growth performance index

surface growth rings, internal annual growth lines and internal tidally deposited microgrowth bands (for review, Richardson 2001). Annually resolved growth rings and lines (checks) have been documented in Callista chione (e.g. Hall et al. 1974; Moura et al. 2009), and the timing of

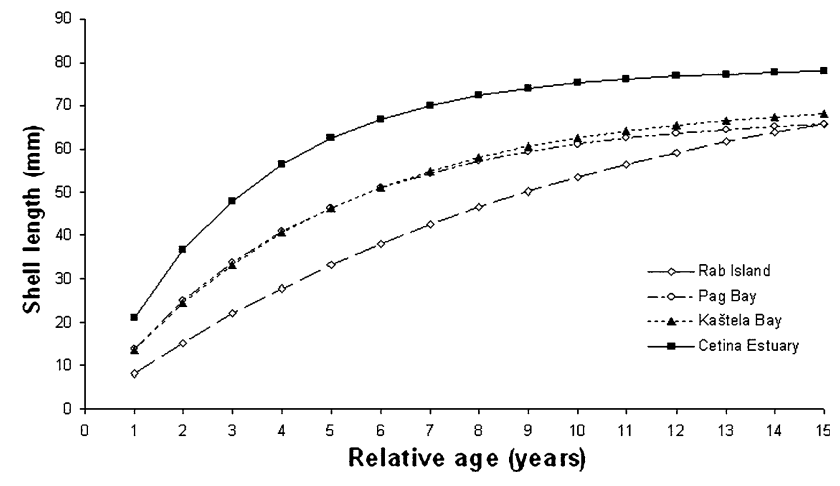

Fig. 8 A comparison of von Bertalanffy growth curves for populations of Callista chione collected from four locations: Rab Island, Pag Bay, Kaštela Bay, and estuary of the Cetina River. The von Bertalanffy growth constants were estimated using Gulland-Holt plots

deposition of the lines with respect to the period of the year has been noted. According to Hall et al. (1974), a dark colored line representing slow growth is deposited annually in $C$. chione collected in the northern part of the Adriatic Sea between July and October. Our results similarly show line deposition occurs in C. chione from Kaštela Bay in the middle of the Adriatic during the summer period. In contrast, in $C$. chione from the southwest coast of Portugal, annual growth lines were deposited between September and January (Moura et al. 2009). Differences in the timing of growth check formation have previously been documented in other species of venerid bivalves. For example, in the Marmara Sea (Turkey), the striped venus Chamelea 
Table 3 Values of von Bertalanffy growth parameters and growth performance index obtained in previous studies: $L_{\infty}$ asymptotic length $(\mathrm{mm})$, $k$ growth constant $\left(k\right.$ year $\left.^{-1}\right)$, $\phi^{\prime}$ growth performance index

\begin{tabular}{llcll}
\hline Study & Location & $L_{\infty}$ & $k$ year $^{-1}$ & $\emptyset^{\prime}$ \\
\hline Forster (1981) & Whitsand Bay (UK) & 105.8 & 0.02 & 2.35 \\
Metaxatos (2004) & Euboikos Gulf (Greece) & 93.0 & 0.24 & 3.32 \\
Leontarakis and & Thassos Island (Greece) & 62.7 & 0.24 & 2.97 \\
Richardson (2005) & & 57.8 & 0.26 & 2.94 \\
Moura et al. (2009) & Arrábida (Portugal) & 98.1 & 0.15 & 3.16 \\
\hline
\end{tabular}

gallina has a slow growth period between October and February (Deval 2001), whereas on the eastern coast of Spain, narrow patterns of shell growth bands, representing periods of slow shell growth, are formed in this species between August and October (Ramón and Richardson 1992) when seawater temperatures are maximal. In the Algarve, southern Portugal, annual growth marks form at the beginning of autumn, especially in October (Gaspar et al. 2004).

Previous age determination studies conducted on C. chione found that the number of internal growth lines closely matched the number of external growth rings (Metaxatos 2004; Leontarakis and Richardson 2005). Smooth clams significantly reduce their growth rate with increasing age. According to Hall et al. (1974), C. chione are growing twice as fast $(9.3 \mathrm{~mm})$ during the third year of life than during their seventh or any later year $(4.7 \mathrm{~mm})$. Keller et al. (2002) found that the growth rate of $C$. chione was relatively fast during the first years of life and that a size of $45 \mathrm{~mm}$ was reached after about 3-4 years, while an apparent decrease in growth rate occurred following the fifth year of life. Smooth clams in the present study grew in a similar fashion, growing rapidly during the first 5 or so years of life and shell growth subsequently slowed down with increasing age. Similar growth rates were observed in shells from the three studied areas, Pag Bay, Kaštela Bay, and Cetina River estuary. However, smooth clams from the Island of Rab had a different growth pattern; annual growth rates were similar up to 10 years of age rather than decreasing as in clams from other studied areas. Observed differences in estimated VBG coefficients using the population data and the incremental data for clams from Rab Island, Pag Bay, and Kaštela Bay are probably caused by methods applied. That is, incremental data were measured only up to the 15 th growth ring and at these locations, significant proportion of population was older than 15 years. At Cetina, younger clams dominated in population resulting in similar VBC coefficients obtained by two methods.

The VBG growth constants recorded in this study are within the range of values obtained by previous authors (Table 3). Obtaining accurate estimates of growth parameters in $C$. chione is important for defining a commercial minimal landing size (MLS). In some parts of the European
Union (EU) waters, excluding the Mediterranean Sea, MLS for $C$. chione is currently $50 \mathrm{~mm}$ (Council Regulation 1298/2000). In the Adriatic waters of Croatia, a MLS has not yet been officially specified; however, only clams larger than $40-50 \mathrm{~mm}$ are usually harvested (Matijaca, pers. comm.). We have estimated that $C$. chione from Cetina River estuary attain this size within 4 years, whereas those from Kaštela Bay require about 5 and those from Pag Bay and Island of Rab about 7 years.

There is no official statistics on the collection of C. chione from natural populations in the Croatian part of the Adriatic Sea. However, in a recently conducted PHARE 2005 project, data on commercial harvesting of $C$. chione were collected using anonymous queries distributed to licensed and unlicensed shellfish collectors (Peharda, unpublished). Twenty-five out of 69 fishermen who responded to anonymous questionnaires harvested C. chione by SCUBA diving, indicating the importance of this clam species in the Croatian shellfish market. The average daily catch of $C$. chione in 2008 was $10.7 \mathrm{~kg}$ per shellfish collector, and the most important harvesting sites were on the west coast of Istria, Starigrad-Paklenica, the Island of Pag and Kaštela Bay. It is important to note that people that participated in this study were cautious in giving data on their catches since it is likely that some of the clams were collected from legally protected areas where shellfish harvesting is prohibited, such as Cetina River estuary, although high rates of exploitation do occur in such places (Ezgeta-Balić, pers. comm.).

The observed local differences in population structure of the clams indicate that there may be different levels of fishing pressure in the areas sampled. A high proportion of the $C$. chione collected from near Rab Island were older than 15 years $(32 \%)$, indicating that there is no or only low fishing pressure in that region. Returns from the socioeconomic survey indicate that this area is not an important fishing ground for $C$. chione. Clams of the other three sampling areas, however, seem to be subject to intensive fishing as is indicated by their generally small size and young ages. It is questionable whether the existing levels of harvesting are sustainable. Metaxatos (2004) showed that C. chione $>10$ years were absent from Euboikos Gulf (Greece) and suggested that this indicated overfishing of the older and larger clams. These Greek populations 
consisted mainly of young clams $<6$ years, which were not subject to fishing. Similarly, in a coastal bay in Greece, almost all clams were younger than 10 years and age classes between 1 and 3 years dominated the populations (Leontarakis and Richardson 2005). Further unregulated increase in the exploitation of $C$. chione in the Croatian part of the Adriatic Sea may in the near future significantly change the age structure of populations and may have longterm effects on the species' sustainable management.

According to previous studies, the bivalve condition index is sensitive to changes in reproductive development and therefore a good indicator of bivalve reproduction (e.g. Gribben et al. 2004; Ojea et al. 2004; Peharda et al. 2006). Moura et al. (2008) noted that changes in body condition index in $C$. chione followed the gametogenic cycle; flesh weight increased prior to spawning and decreased during spawning. Previous studies of gonad development in $C$. chione have indicated that this bivalve is capable of year-round reproduction, having a prolonged reproductive cycle with simultaneous presence of gametes in various stages of maturation (Metaxatos 2004; Moura et al. 2008). In our study, three peaks in condition index were noted, i.e. in July, January and March, indicating several reproductive events within a year. In the coastal waters of southwest Portugal, $C$. chione showed three spawning peaks between January and October (Moura et al. 2008). The occurrence of several reproductive peaks throughout the breeding season is likely to be an adaptation that favors, by risk spreading, successful recruitment rather than relying on the survival of one large cohort per year.

Callista chione does not begin gametogenesis until it attains a length of at least $30 \mathrm{~mm}$, and the size at first maturity for this species is $\sim 51 \mathrm{~mm}$ (Moura et al. 2008). Fecundity in bivalves is size-related and in the largest animals, most production $(>90 \%)$ is channeled into gamete synthesis (Gosling 2003). The relatively large size of $C$. chione at first maturity along with the results of the present and earlier studies on $C$. chione growth rates (Hall et al. 1974; Forster 1981; Keller et al. 2002; Leontarakis and Richardson 2005; Moura et al. 2009) indicate that shell growth is all but negligible after the tenth year of life and that in exploited populations, clams older than 10 years represent only a small proportion of the population (Metaxatos 2004; Leontarakis and Richardson 2005). These observations indicate that if most of the large, fecund clams are harvested, serious declines in $C$. chione populations in the Croatian Adriatic may be expected to occur.

Acknowledgments This research was financed by support from the European Commission PHARE 2005 project "Assessment of demersal fish and shellfish stocks commercially exploited in Croatia", Croatian Ministry of Science and Technology grant No. 0010013077-0532 "Biodiversity and sustainable management of pelagic and demersal resources in the Adriatic" and funding from the School of Ocean Sciences, Bangor University. The authors are grateful to Ivica Matijaca and Leo Brajković for technical assistance. Special thanks to Barbara Zorica for her help with the statistical analysis.

\section{References}

Davenport J, Chen X (1987) A comparison of methods for the assessment of condition in the mussel (Mytilus edulis L.). J Mollus Stud 53:293-297

Deval MC (2001) Shell growth and biometry of the striped venus Chamelea gallina (L) in the Marmara Sea, Turkey. J Shellfish Res 20:155-159

Forster GR (1981) The age and growth of Callista chione. J Mar Biol Assoc UK 61:881-883

Gaspar MB, Pereira AM, Vasconcelos P, Monteiro CC (2004) Age and growth of Chamelea gallina from the Algarve coast (southern Portugal): influence of seawater temperature on gametogenic cycle and growth rate. J Mollus Stud 70:371-377

Gosling E (2003) Bivalve molluscs-biology, ecology and culture. Fishing News Books, Blackwell Publishing, Oxford

Gribben PE, Helson J, Jeffs AG (2004) Reproductive cycle of the New Zealand Geoduck, Panopea zelandica, in two North Island populations. Veliger 47:53-65

Hall CA Jr, Dollase WA, Corbató CE (1974) Shell growth in Tivela stultorum (Mawe, 1823) and Callista chione (Linnaeus, 1758) (Bivalvia): annual periodicity, latitudinal differences, and diminution with age. Palaeogeogr Palaeocl 15:33-61

Keller N, Del Piero D, Longinelli A (2002) Isotopic composition, growth rates and biological behaviour of Chamelea gallina and Callista chione from the Gulf of Trieste (Italy). Mar Biol 140:9-15

Leontarakis PK, Richardson CA (2005) Growth of the smooth clam, Callista chione (Linnaeus, 1758) (Bivalvia: Veneridae) from the Thracian Sea, northeastern Mediterranean. J Mollus Stud 71:189-198

Metaxatos A (2004) Population dynamics of the venerid bivalve Callista chione (L.) in a coastal area of the eastern Mediterranean. J Sea Res 52:293-305

Moura P, Gaspar MB, Monteiro CC (2008) Gametogenic cycle of the smooth clam Callista chione on the south-western coast of Portugal. J Mar Biol Assoc UK 88(1):161-167. doi:10.1017/ S0025315408000337

Moura P, Gaspar MB, Monteiro CC (2009) Age determination and growth rate of a Callista chione population from the southwestern coast of Portugal. Aquat Biol 5:97-106. doi:10.3354/ ab00119

Ojea J, Pazos AJ, Martínez D, Novoa S, Sánchez JL, Abad M (2004) Seasonal variation in weight and biochemical composition of the tissues of Ruditapes decussatus in relation to the gametogenic cycle. Aquaculture 238:451-469. doi:10.1016/j.aquaculture. 2004.05.022

Peharda M, Mladineo I, Bolotin J, Kekez L, Skaramuca B (2006) The reproductive cycle and potential protandric development of the Noah's Ark shell. Arca noae L.: Implications for aquaculture. Aquaculture 252:317-327. doi:10.1016/j.aquaculture.2005. 07.007

Peharda M, Ezgeta Balić D, Vrgoč N, Isajlović I, Bogner D (2010) Bivalve community structure in the Croatian part of the Adriatic Sea-a hydraulic dredge survey. Acta Adriat 51 (in press)

Poppe GT, Goto Y (2000) European seashells volume II (Scaphopoda, Bivalvia, Cephalopoda). ConchBooks, Hackenheim

Ramón M, Richardson CA (1992) Age determination and shell growth of Chamelea gallina (Bivalvia: Veneridae) in the western Mediterranean. Mar Ecol Prog Ser 89:15-23 
Richardson CA (2001) Molluscs as archives of environmental change. Oceanogr Mar Biol Ann Rev 39:103-164

Richardson CA, Crisp DJ, Runham NW (1979) Tidally deposited growth bands in the shell of the common cockle Cerastoderma edule (L.). Malacologia 18:277-290

Sparre P, Venema SC (1998) Introduction to tropical fish stock assessment. Part 1, Manual. FAO fisheries technical paper. No. 306/1, Rev. 2. Rome, FAO
Tirado C, Salas C, López JI (2002) Reproduction of Callista chione L., 1758 (Bivalvia: Veneridae) in the littoral of Málaga (southern Spain). J Shellfish Res 21:643-648

Zavodnik D, Šimunović A (1997) Beskralješnjaci morskog dna Jadrana. Svjetlost, Sarajevo 